\title{
Historical trends in the epidemiology of candidaemia: analysis of an 11-year period in a tertiary care hospital in Brazil
}

\author{
Marcos Paulo Wille ${ }^{1}$, Thaís Guimarães ${ }^{1 /+}$, \\ Guilherme Henrique Campos Furtado², Arnaldo Lopes Colombo ${ }^{1}$
}

\author{
'Laboratório Especializado em Micologia ${ }^{2}$ Comissão de Controle de Infecção Hospitalar, \\ Departamento de Doenças Infecciosas, Universidade Federal de São Paulo, São Paulo, SP, Brasil
}

\begin{abstract}
Candida species are an important cause of bloodstream infections (BSI). To evaluate the epidemiological, clinical and microbiological aspects of two cohorts \{1994-1999 [period 1 (P1)]; 2000-2004 [period 2 (P2)]\} of candidaemic patients, we performed a retrospective analysis from a laboratory-based survey. A total of 388 candidaemias were identified, with an incidence of 0.20/1,000 patient-days and a significant increase in P2 vs. P1 $(0.25 \mathrm{vs} .0 .15, p$ $=0.04$ ). Cancer and prior antibiotic use were frequent and Candida albicans was the most prevalent species found (42.4\%). Resistance to fluconazole was found in $2.47 \%$ of the strains. No differences were observed in the species distribution of Candida during the study periods. In the P2 cohort, there were higher prevalence of elderly individuals, cardiac, pulmonary and liver diseases, renal failure, central venous catheters and antibiotic therapy. In P1, there were higher prevalence of neurological diseases and chemotherapy. The crude mortality was $55.4 \%$. In conclusion, our incidence rates remained high. Furthermore, the distribution pattern of Candida species and the fluconazole resistance profile remained unchanged. Moreover, we found a clear trend of higher prevalence of candidaemia among the elderly and among patients with comorbidities. Finally, it is necessary to discuss strategies for the prevention and control of Candida BSI in Brazil.
\end{abstract}

Key words: candidaemia - epidemiology - bloodstream infections

Bloodstream infections (BSI) caused by Candida species are an important cause of morbidity and mortality in hospitalised patients worldwide (Zaoutis et al. 2005, Odds et al. 2007, Pfaller \& Diekema 2007, Hsueh \& Ruan 2009). Candidaemia is generally difficult to diagnose and treat and mortality rates remain at approximately $50 \%$, with great costs to the healthcare system (Gudlaugsson et al. 2003, Colombo et al. 2008, Arnold et al. 2010).

In Brazil, several investigators have described the epidemiology of candidaemia in tertiary care hospitals. The incidence rate of candidaemia continues to be high, with incidence rates ranging from 1.27-2.49 per 1,000 admissions (Colombo et al. 2006, 2007, França et al. 2008, Girão et al. 2008, Motta et al. 2010, Pereira et al. 2010). Conversely, studies undertaken in tertiary hospitals in the United States and several European countries have shown lower incidence rates, ranging from 0.28-0.96 and 0.02-1.08 per 1,000 admissions, respectively (Hajjeh et al. 2004, Tortorano et al. 2004, Almirante et al. 2005, Zilberberg et al. 2008, Poikonen et al. 2010, Arendrup et al. 2011, Das et al. 2011)

Almost all of the previous Brazilian candidaemia studies have been conducted during short periods of time, which preclude proper conclusions regarding temporal trends of Candida distribution, incidence rates and epidemiological characteristics of the populations (Nuc-

+ Corresponding author: tguimaraes@terra.com.br

Received 22 July 2012

Accepted 7 December 2012 ci et al. 2010). This retrospective study was conducted to evaluate the historical trends of incidence rates and epidemiological characteristics of all of the candidaemia cases documented at a large tertiary care hospital in Brazil during an 11-year period from 1994-2004.

\section{SUBJECTS, MATERIALS AND METHODS}

Surveillance - This study has merged three databases that include information regarding all candidaemia patients admitted to Hospital São Paulo between January 1994-December 2004. Hospital São Paulo is a universityaffiliated tertiary care centre with 743 beds, of which 121 are for the intensive care unit in São Paulo, Brazil. Hospital São Paulo attends to cases of high complexity, including solid organ and haematopoietic stem cell transplants.

The databases were composed of clinical and laboratory data. Briefly, an investigator was trained to search for positive blood cultures in the microbiology laboratory on a daily basis. When a candidaemia episode was identified, the clinical and epidemiological data were prospectively collected in a standardised case report form. The form contained the following information: age, gender, date of admission, ward, date of candidaemia, underlying conditions, exposure to invasive medical procedures, use of antibiotics or corticosteroid drugs, management of candidaemia (antifungal treatment, catheter removal) and outcome (in-hospital mortality). Hospital laboratory audits were performed periodically to ensure that no cases of candidaemia were missed. In addition, medical records audits were sporadically performed on $10 \%$ of the cases to verify the accuracy and completeness of the data. The protocol was approved by the local Ethical Committee. 
Case definition - An episode of candidaemia was defined as the incident isolation of Candida spp from a blood culture (BACTEC system) of a patient with symptoms suggestive of BSI. Briefly, a fever was defined as an axillary temperature $>37.8^{\circ} \mathrm{C}$, hypotension as systolic blood pressure $<90 \mathrm{mmHg}$ and neutropaenia as an absolute neutrophil count $<500 / \mathrm{mm}^{3}$. The demographics, clinical characteristics, risk factors and outcomes (in-hospital mortality) were compared between the two periods. Candidaemia occurring $>30$ days after the incident isolation was defined as a new episode.

Yeast identification - All Candida species recovered from the blood cultures were sent to the Special Mycology Laboratory at Federal University of São Paulo for species identification and determination of antifungal susceptibility. The isolates were identified according to their microscopic morphology on corneal Tween 80 agar and by biochemical tests using the ID 32C system (bioMérieux). Susceptibility testing to fluconazole was performed by the broth microdilution assay according to the methods recommended by the Clinical and Laboratory Standards Institute (CLSI 2002). The isolates with minimal inhibitory concentration (MICs) of $8 \mu \mathrm{g} / \mathrm{mL}$ fluconazole were considered susceptible. The isolates with MICs of 16 and $32 \mu \mathrm{g} / \mathrm{mL}$ were considered susceptible in a dose-dependent (SDD) manner and the isolates with MICs of $64 \mu \mathrm{g} / \mathrm{mL}$ were considered resistant.

Statistical analysis - The number of admissions and patient-days was collected. The incidence rates were calculated as the number of candidaemias per 1,000 admissions and per 1,000 patient-days. The overall incidence was determined using summed denominators of patientdays and admissions to calculate pooled mean rates. The analysis of the incidence rates and species distribution patterns were arbitrarily performed considering two intervals: 1994-1999 [period 1 (P1)] and 2000-2004 [period 2 (P2)]. The statistical analysis was performed by the $\mathrm{X}^{2}$ or Fisher's exact test for categorical variables or the Student's $t$ test for continuous variables with Statistical Package for the Social Sciences software 15.0 (Chicago, IL). All of the tests of statistical significance were twosided, with a significance level set at 0.05 .

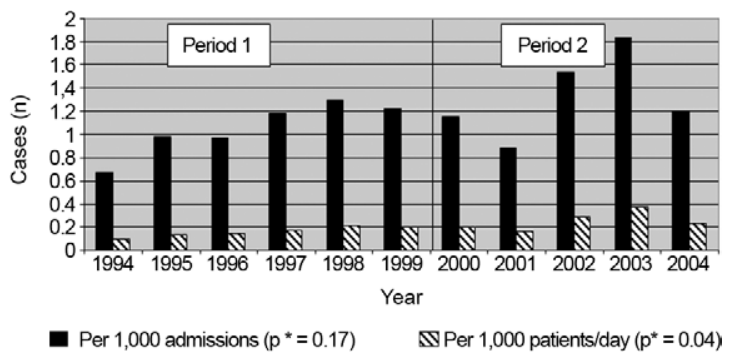

Fig. 1: incidence rates of candidaemia at Hospital São Paulo (1994-2004). Asterisks mean significant differences between the two periods.

\section{RESULTS}

We detected a total of 388 episodes of candidaemia during the surveillance period. Of these, $60.3 \%$ of the patients were males and the mean and median age was 32.4 and 30 years, respectively (range $0-99$ years). The overall incidence rate was 1.20 episodes per 1,000 admissions and 0.20 episodes per 1,000 patient-days. Fig. 1 shows the incidence rate of candidaemia, which ranged from 0.68-1.84 cases per 1,000 admissions and 0.09-0.37 cases per 1,000 patient-days.

The demographics, clinical characteristics, risk factors and outcomes (in-hospital mortality) are displayed in Table I. Most of the candidaemia cases occurred in the adult intensive care unit $(85 / 388,21.9 \%)$ or the paediatric intensive care unit $(66 / 388,17 \%)$. Underlying diseases were present in $97.4 \%$ (378/388) of the patients. Cancer was the most frequent underlying disease $(103 / 378,31.7 \%)$, followed by renal failure $(43 / 378,11 \%)$, pulmonary disease $(32 / 378,8.2 \%)$ and diabetes mellitus $(31 / 378,7.9 \%)$. Overall, the use of prior antibiotic therapy was documented in $93.2 \%(362 / 388)$ of the cases. The insertion of a central line was reported in $72.9 \%$ (283/388) of the patients. The presence of clinical manifestations could be evaluated in only 302 patients. Fever, hypotension and hypothermia were present in $88.4 \%$ (267/302), $6.9 \%(21 / 302)$ and $17.2 \%$ (52/302) of the patients, respectively. Candida albicans was the most prevalent species found (165 cases, 42.4\%), followed by Candida tropicalis (106 cases, 27.3\%) and Candida parapsilosis (85 cases, $21.9 \%$ ). Candida glabrata and Candida krusei comprised only $4.4 \%$ and $1 \%$ of the cases, respectively (Table II).

Susceptibility testing to fluconazole was undertaken for $323(83.2 \%)$ Candida strains. SDD and resistance were found in $2.47 \%(8 / 323)$ of the strains. The species that were most prevalent for the SDD or resistance phenotypes were C. krusei $(2 / 3,66.7 \%)$ and C. glabrata $(2 / 15,13.3 \%)$. No resistant isolates were found among the C. albicans, C. parapsilosis or C. tropicalis strains. Overall, antifungal therapy was administered for $69.5 \%$ (270/388) of the cases. Of these, amphotericin B desoxicolate and fluconazole were used by $88.8 \%$ (239/270) and $11.1 \%(30 / 270)$ of the patients, respectively.

There was a significant increase in the incidence of candidaemia per 1,000 patient-days in $\mathrm{P} 2$ compared with P1 $(0.25$ vs. $0.15, p=0.04)$. In contrast, the difference in incidence rates of candidaemia per 1,000 admissions between the two periods was not significant (1.05 vs. 1.32, $\mathrm{p}=0.17$ ), as illustrated in Fig. 1 .

The mean age of the patients with candidaemia was 27.2 years and 36.3 years for $\mathrm{P} 1$ and $\mathrm{P} 2$, respectively. In $\mathrm{P} 2$, there were higher prevalence of central venous catheters and antibiotic therapy compared with P1. In P2 we observed higher prevalence of individuals with older age, cardiac disease, pulmonary disease, liver disease and renal failure. Conversely, in the first period, there was a higher prevalence of patients with neurological disease and exposure to chemotherapy. The main epidemiologic characteristics of the patients analysed in the two study periods are summarised in Table I.

The distribution of the Candida species causing candidaemia was evaluated to identify possible trends through- 
out the study period. We found no differences in the distribution of the four major species of Candida (Fig. 2).

We noted that a significant number of candidaemic patients in both study periods were not treated: $31 \%$ $(52 / 165$ cases) vs. $30 \%$ (66/223 cases), respectively ( $p=$ 0.68 ). The average rate of crude in-hospital mortality was $55.4 \%$. The in-hospital mortality rate was $53.9 \%(89 / 165)$ for $\mathrm{P} 1$ and $56.5 \%(126 / 223)$ for $\mathrm{P} 2(\mathrm{p}=0.61)$. The average time between the diagnosis of candidaemia and death was 15 days for $\mathrm{P} 1$ and 19 days for $\mathrm{P} 2(\mathrm{p}=0.48)$.

\section{DISCUSSION}

The present study has consolidated important epidemiologic findings of candidaemia in our institution. We found an incidence rate of 1.20 infections per 1,000 hospital admissions. This is similar to the incidence rates published by other groups in our country (Colombo et al. 2007, França et al. 2008, Girão et al. 2008, Nucci et al. 2010), but consistently higher than studies conducted in the northern hemisphere. Epidemiological studies performed in tertiary care hospitals in Europe and the United States have shown incidence rates ranging from 0.02-1.08 cases per 1,000 hospital admissions (Hajjeh et al. 2004, Tortorano et al. 2004, Almirante et al. 2005, Zilberberg et al. 2008, Poikonen et al. 2010, Arendrup et al. 2011, Das et al. 2011).

The explanations for the high rates of candidaemia at our institution were not specifically addressed in our study, but possible factors, such as differences in the availability of resources for medical care and training programs, difficulties in the implementation of infection control programs in hospitals in developing countries, the limited number of healthcare workers for assisting patients in critical care units and less aggressive empirical antifungal therapy practices and prophylaxis for highrisk patients have been discussed elsewhere (Colombo et al. 2007). In addition, we found a significant increase in the candidaemia incidence rate per 1,000 patient-days in the second period of data collection compared with the first period. Comparing the two periods, we observed that P2 had a higher prevalence of patients exhibiting the following comorbidities: cancer, renal failure, lung disease, diabetes mellitus and cardiac disease. The higher prevalence of older patients, as well as individuals with multiple degenerative diseases in P2 may help explain the higher incidence of candidaemia in that period. This

TABLE I

Comparative analysis of the demographic and clinical characteristics of 388 cases of candidaemia documented in period 1 (P1) (1994-1999) and period 2 (P2) (2000-2004)

\begin{tabular}{|c|c|c|c|c|}
\hline Variables & $\begin{array}{c}\mathrm{P} 1 \\
\mathrm{n}=165 \\
\mathrm{n}(\%)\end{array}$ & $\begin{array}{c}\mathrm{P} 2 \\
\mathrm{n}=223 \\
\mathrm{n}(\%)\end{array}$ & $\begin{array}{c}\text { Overall } \\
\mathrm{n}=388 \\
\mathrm{n}(\%)\end{array}$ & $\mathrm{p}$ \\
\hline Male gender & $99(60)$ & $135(60.5)$ & $234(60.3)$ & 0.915 \\
\hline Mean age, years (range) & 27.2 & 36.3 & $32.4(0-99)$ & 0.002 \\
\hline Length of hospital stay until candidaemia, days (range) & 19 & 19 & $19(0-367)$ & 0.218 \\
\hline Median time until death, days & 7 & 8 & 8 & 0.481 \\
\hline \multicolumn{5}{|l|}{ Underlying diseases } \\
\hline Cancer & $44(26.7)$ & $79(35.4)$ & $123(31.7)$ & 0.067 \\
\hline Neutropaenia & $29(17.6)$ & $32(14.3)$ & $61(15.7)$ & 0.388 \\
\hline Cardiac disease & $4(2.4)$ & $23(10.3)$ & $27(6.9)$ & 0.003 \\
\hline Pulmonary disease & 0 & $32(14.3)$ & $32(8.2)$ & $<0.001$ \\
\hline Liver disease & $3(1.8)$ & $16(7.2)$ & $19(4.8)$ & 0.016 \\
\hline Neurologic disease & $11(6.7)$ & $4(1.8)$ & $15(3.8)$ & 0.014 \\
\hline Diabetes mellitus & $12(7.3)$ & $19(8.5)$ & $31(7.9)$ & 0.654 \\
\hline Renal failure & $12(7.3)$ & $31(13.9)$ & $43(11)$ & 0.040 \\
\hline Organ transplant recipients & $3(1.8)$ & $7(3.1)$ & $10(1.8)$ & 0.523 \\
\hline Human immunodeficiency virus infection & $5(3)$ & $4(1.8)$ & $9(2.3)$ & 0.507 \\
\hline \multicolumn{5}{|l|}{ Coexisting exposures } \\
\hline Use of corticosteroids & $69(41.8)$ & $105(47.1)$ & $174(44.8)$ & 0.302 \\
\hline Dialysis & $11(6.7)$ & $21(9.4)$ & $32(8.2)$ & 0.330 \\
\hline Chemotherapy & $28(17)$ & $22(9.9)$ & $50(12.8)$ & 0.039 \\
\hline Previous surgery & $66(40)$ & $95(42.6)$ & 161(41.4) & 0.607 \\
\hline Central venous catheter & $113(68.5)$ & $170(76.2)$ & $283(72.9)$ & 0.089 \\
\hline Parenteral nutrition & $66(40)$ & $73(32.7)$ & $139(35.8)$ & 0.140 \\
\hline Prior antibiotic therapy & $154(93.3)$ & $208(93.3)$ & $362(93.2)$ & 0.981 \\
\hline No antifungal treatment & $52(31)$ & $66(30)$ & $118(30.4)$ & 0.680 \\
\hline Crude in-hospital mortality & $89(53.9)$ & $126(56.5)$ & $215(55.4)$ & 0.610 \\
\hline
\end{tabular}


significant increase in the incidence rate between the two periods was not observed when using the other denominator (number of admissions). This fact might be explained by the higher number of admissions in P2.

The median age of the cases enrolled in our study was 29 years, a finding that is in accordance with other Brazilian studies, in which paediatric patients accounted for a large number of candidaemia cases (Colombo et al. 2006, 2008, França et al. 2008). Indeed, a total of 151 patients $(38.9 \%)$ with candidaemia were $<13$ years old. This statistic corroborates the finding of high participation of paediatric patients in different candidaemia casuistic published in Brazil. The mean age of patients with candidaemia observed in P2 was slightly higher than P1. However, the percentage of adults in our candidaemia study is still proportionally lower than that found in developed countries (Colombo et al. 2008, Nucci et al. 2010).

In this study, nearly $40 \%$ of the candidaemia cases occurred in intensive care units (adult and paediatric). This finding is in accordance with previous surveillance studies, in which haematogenous candidiasis has frequently been found in intensive care units (Blot et al. 2001, Blumberg et al. 2001, Kibbler et al. 2003, Fujitani et al. 2006, Girão et al. 2008).

\section{TABLE II}

Species distribution of Candida isolated from 388 cases candidaemia

\begin{tabular}{lc}
\hline Species & $\mathrm{n}(\%)$ \\
\hline Candida albicans & $165(42.5)$ \\
Candida tropicalis & $106(27.3)$ \\
Candida parapsilosis & $85(21.9)$ \\
Candida glabrata & $17(4.4)$ \\
Candida guilliermondii & $6(1.5)$ \\
Candida krusei & $4(1)$ \\
Candida peliculosa & $1(0.3)$ \\
Others & $4(1)$ \\
\hline Total & $388(100)$ \\
\hline
\end{tabular}

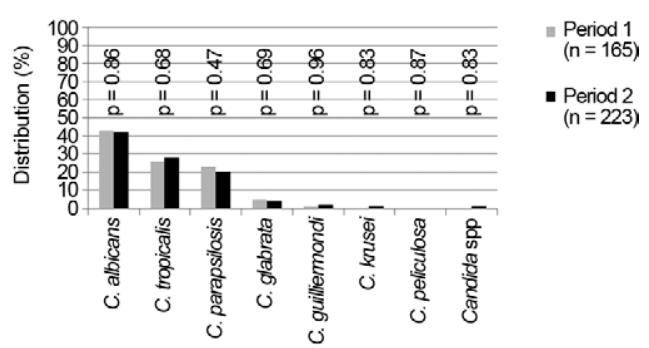

Fig. 2: distribution (\%) of Candida species causing candidaemia at Hospital São Paulo (1994-2004). p: significant differences between the two periods.
Cancer, renal failure, lung disease, diabetes mellitus and cardiac disease were the major underlying diseases among patients with candidaemia in our study, a finding that is consistent with other studies (Nucci et al. 2010). Potential risk factors associated with candidaemia, such as the previous use of antimicrobial drugs, central lines, the use of corticosteroids, parenteral nutrition and surgery, were also identified in our study (Wey et al. 1988, Colombo et al. 2006, 2008, Sofair et al. 2006, St-Germain et al. 2008, Poikonen et al. 2010).

C. albicans, C. parapsilosis and C. tropicalis were the most prevalent Candida species in our study. These data are similar to previous studies conducted in Brazil prior to 2005, in which C. tropicalis and C. parapsilosis were the most prevalent non-albicans species causing candidaemia (Colombo et al. 1999, 2006, Costa et al. 2000, Girão et al. 2008, Nucci et al. 2010). However, studies published after 2005 have found that C. glabrata is emerging as an important aetiologic agent of candidaemia in some Brazilian medical centres (Pasqualotto et al. 2008, Sampaio Camargo et al. 2010).

Fluconazole resistance was a rare finding in our study and restricted to a few isolates, mainly represented by $C$. krusei and C. glabrata strains. It is noteworthy that we did not find fluconazole-resistant strains among the three most prevalent species in our study (C. albicans, $C$. parapsilosis and C. tropicalis).

Only $69.5 \%$ of the patients received antifungal treatment after the diagnosis of candidaemia. The reasons for this worrisome situation were not evaluated. However, we suspect that difficulties in establishing an early diagnosis of candidaemia played a major role. The crude mortality of candidaemia was $55.4 \%$, a finding that is compatible with results from other Brazilian studies (Colombo et al. 2006, 2008, Girão et al. 2008). It is noteworthy that this mortality rate was similar in both study periods (approximately 55\%). Considering that antifungal resistance was rare in our study, the factors related to unfavourable outcomes were likely the severity of the illness and late diagnosis of candidaemia.

In conclusion, our study demonstrated a significant increase in the incidence of candidaemia in a tertiary care hospital in Brazil. Overall, our incidence rates have remained higher than those reported in medical centres of the northern hemisphere. The distribution pattern and fluconazole resistance profile of Candida species have remained unchanged. Moreover, we found a clear trend of higher prevalence of candidaemia among elderly patients and patients with comorbidities. Finally, it is clear that new strategies for the prevention and control of haematogenous Candida infections should be discussed in our region.

\section{REFERENCES}

Almirante B, Rodríguez D, Park BJ, Cuenca-Estrella M, Planes AM, Almela M, Mensa J, Sanchez F, Ayats J, Gimenez M, Saballs P, Fridkin SK, Morgan J, Rodriguez-Tudela JL, Warnock DW, Pahissa A, Barcelona Candidemia Project Study Group 2005. Epidemiology and predictors of mortality in cases of Candida bloodstream infection: results from population-based surveillance, Barcelona, Spain, from 2002 to 2003. J Clin Microbiol 43: 1829-1835. 
Arendrup MC, Bruun B, Christensen JJ, Fuursted K, Johansen HK, Kjaeldgaard P, Knudsen JD, Kristensen L, Moller J, Nielsen L, Rosenvinge FS, Roder B, Schonheyder HC, Thomsen MK, Truberg K 2011. National surveillance of fungemia in Denmark (2004 to 2009). J Clin Microbiol 49: 325-334.

Arnold HM, Micek ST, Shorr AF, Zilberberg MD, Labelle AJ, Kothari S, Kollef MH 2010. Hospital resource utilization and costs of inappropriate treatment of candidemia. Pharmacotherapy 30: 361-368.

Blot S, Vandewoude K, Hoste E, Poelaert J, Colardyn F 2001. Outcome in critically ill patients with candidal fungaemia: Candida albicans vs. Candida glabrata. J Hosp Infect 47: 308-313.

Blumberg HM, Jarvis WR, Soucie JM, Edwards JE, Patterson JE, Pfaller MA, Rangel-Frausto MS, Rinaldi MG, Saiman L, Wiblin RT, Wenzel RP, National Epidemiology of Mycoses Survey (NEMIS) Study Group 2001. Risk factors for candidal bloodstream infections in surgical intensive care unit patients: the NEMIS prospective multicenter study. The national epidemiology of mycosis survey. Clin Infect Dis 33: 177-186.

CLSI - Clinical and Laboratory Standards Institute 2002. Reference method for broth dilution antifungal susceptibility testing of yeasts: approved standard, document M27-A2, 2nd ed., CLSI, Pennsylvania, 29 pp.

Colombo AL, Guimarães T, Silva LR, de Almeida Monfardini LP, Cunha AK, Rady P, Alves T, Rosas RC 2007. Prospective observational study of candidemia in São Paulo, Brazil: incidence rate, epidemiology and predictors of mortality. Infect Control Hosp Epidemiol 28: 570-576.

Colombo AL, Nucci M, Park BJ, Nouér SA, Arthington-Skaggs B, da Matta DA, Warnock D, Morgan J, Brazilian Network Candidemia Study 2006. Epidemiology of candidemia in Brazil: a nationwide sentinel surveillance of candidemia in eleven medical centers. J Clin Microbiol 44: 2816-2823.

Colombo AL, Nucci M, Salomão R, Branchini ML, Richtmann R, Derossi A, Wey SB 1999. High rate of non-albicans candidemia in Brazilian tertiary care hospitals. Diagn Microbiol Infect Dis 34: $281-286$.

Colombo AL, Thompson L, Graybill JR 2008. The north and south of candidemia: issues for Latin America. Drugs Today 44 (Suppl. A): 1-34.

Costa SF, Marinho I, Araújo EA, Manrique AE, Medeiros EA, Levin AS 2000. Nosocomial fungemia: a 2-year prospective study. $J$ Hosp Infect 45: 69-72.

Das I, Nightingale P, Patel M, Jumaa P 2011. Epidemiology, clinical characteristics and outcome of candidemia: experience in a tertiary referral centre in the UK. Int J Infect Dis 15: e759-763.

França JC, Ribeiro CE, Queiroz-Telles F 2008. Candidemia in a Brazilian tertiary care hospital: incidence, frequency of different species, risk factors and antifungal susceptibility. Rev Soc Bras Med Trop 41: 23-28.

Fujitani S, Ricardo-Dukelow M, Kamiya T, Sullivan L, Low L 2006. Ethnicity and other possible risk factors for candidemia at 3 tertiary care university hospitals in Hawaii. Infect Control Hosp Epidemiol 27: 1261-1263.

Girão E, Levin AS, Basso M, Gobara S, Gomes LB, Medeiros EA, Costa SF 2008. Seven-year trend analysis of nosocomial candidemia and antifungal (fluconazole and caspofungin) use in intensive care units at a Brazilian university hospital. Med Mycol 46: 581-588.

Gudlaugsson O, Gillespie S, Lee K, Vande Berg J, Hu J, Messer S, Herwaldt L, Pfaller M, Diekema D 2003. Attributable mortality of nosocomial candidemia, revisited. Clin Infect Dis 37: 1172-1177.

Hajjeh RA, Sofair AN, Harrison LH, Lyon GM, Arthington-Skaggs BA, Mirza SA, Phelan M, Morgan J, Lee-Yang W, Ciblak MA, Benjamin LE, Sanza LT, Huie S, Yeo SF, Brandt ME, Warnock DW 2004. Incidence of bloodstream infections due to Candida species and in vitro susceptibilities of isolates collected from 1998 to 2000 in a population based active surveillance program. J Clin Microbiol 42: 1519-1527.

Hsueh PR, Ruan SY 2009. Invasive candidiasis: an overview from Taiwan. J Formos Med Assoc 108: 443-451.

Kibbler CC, Seaton S, Barnes RA, Gransden WR, Holliman RE, Johnson EM, Perry JD, Sullivan DJ, Wilson JA 2003. Management and outcome of bloodstream infections due to Candida species in England and Wales. J Hosp Infect 54: 18-24.

Motta AL, Almeida GM, Almeida Júnior JN, Burattini MN, Rossi F 2010. Candidemia epidemiology and susceptibility profile in the largest Brazilian teaching hospital complex. Braz J Infect Dis 14: 441-448.

Nucci M, Queiroz-Telles F, Tóbon AM, Restrepo A, Colombo AL 2010. Epidemiology of opportunistic fungal infections in Latin America. Clin Infect Dis 51: 561-570.

Odds FC, Hanson MF, Davidson AD, Jacobsen MD, Wright P, Whyte JA, Gow NA, Jones BL 2007. One year prospective survey of Candida bloodstream infections in Scotland. J Med Microbiol 56: 1066-1075.

Pasqualotto AC, Zimerman RA, Alves SH, Aquino VR, Branco D, Wiltgen D, do Amaral A, Cechinel R, Colares SM, da Rocha IG, Severo LC, Sukiennik TC 2008. Take control over your fluconazole prescriptions: the growing importance of Candida glabrata as an agent of candidemia in Brazil. Infect Control Hosp Epidemiol 29: 898-899.

Pereira GH, Müller PR, Szeszs MW, Levin AS, Melhem MS 2010. Five-year evaluation of bloodstream yeast infections in a tertiary hospital: the predominance of non-albicans Candida species. Med Mycol 48: 839-842.

Pfaller MA, Diekema DJ 2007. Epidemiology of invasive candidiasis: a persistent public health problem. Clin Microbiol Rev 20: 133-163.

Poikonen E, Lyytikäinen O, Anttila VJ, Koivula I, Lumio J, Kotilainen P, Syrjälä H, Ruutu P 2010. Secular trend in candidemia and the use of fluconazole in Finland, 2004-2007. BMC Infect Dis 28: 312.

Sampaio Camargo TZ, Marra AR, Silva CV, Cardoso MF, Martino MD, Camargo LF, Correa L 2010. Secular trends of candidemia in a tertiary care hospital. Am J Infect Control 38: 546-551.

Sofair AN, Lyon GM, Huie-White S, Reiss E, Harrison LH, Sanza LT, Arthington-Skaggs BA, Fridkin SK 2006. Epidemiology of community-onset candidemia in Connecticut and Maryland. Clin Infect Dis 43: 32-39.

St-Germain G, Laverdière M, Pelletier R, René P, Bourgault AM, Lemieux C, Libman M 2008. Epidemiology and antifungal susceptibility of bloodstream Candida isolates in Quebec: report on 453 cases between 2003 and 2005. Can J Infect Dis Med Microbiol 19: 55-62.

Tortorano AM, Peman J, Bernhardt H, Klingspor L, Kibbler CC, Faure O, Biraghi E, Canton E, Zimmermann K, Seaton S, Grillot R, ECMM Working Group on Candidaemia 2004. Epidemiology of candidaemia in Europe: results of 28-month European Confederation of Medical Mycology (ECMM) hospital-based surveillance study. Eur J Clin Microbiol Infect Dis 23: 317-322.

Wey SB, Mori M, Pfaller MA, Woolson RF, Wenzel RP 1988. Hospital-acquired candidemia: the attributable mortality and excess length of stay. Arch Intern Med 148: 2642-2645.

Zaoutis TE, Argon J, Chu J, Berlin JA, Walsh TJ, Feudtner C 2005. The epidemiology and attributable outcomes of candidemia in adults and children hospitalized in the United States: a propensity analysis. Clin Infect Dis 41: 1232-1239.

Zilberberg MD, Shorr AF, Kollef MH 2008. Secular trends in candidemia-related hospitalization in the United States, 2000-2005. Infect Control Hosp Epidemiol 29: 978-980. 